\title{
AUTOGENEALOGIA E REIVINDICAÇÃO DE OBJETIVIDADE MORAL EM NIETZSCHE ${ }^{12}$
}

Jorge Luiz Viesenteiner (UFES) ${ }^{3}$

jvies@uol.com.br

Resumo: O objetivo do artigo é articular os conceitos de autogenealogia e de reivindicação de objetividade moral, na medida em que exploro a fecundidade da noção de autorreferencialidade do argumento autogenealógico, e de uma concepção deflacionada de objetividade, onde o mais importante é o controle sobre o conteúdo dos juízos morais, e menos a verdade correspondencial desses juízos. Para isso, lanço mão de algumas categorias do debate contemporâneo em metaética, de modo sustentar que Nietzsche ocupa uma posição não-cognitivista, mas com algum sucesso de reivindicação de objetividade moral.

Palavras-chave: Autogenealogia; autorreferencialidade; objetividade; metaética.

\section{INTRODUÇÃO}

Quando levamos a sério a avaliação que Nietzsche faz sobre si mesmo, a saber, a consideração de seu "modo de ser" como "afirmativo" (CI, O que os alemães estão perdendo 6; KSA 6, p. 108) ${ }^{4}$, a discussão sobre os limites e alcances pro-

\footnotetext{
${ }^{1}$ Esta pesquisa é financiada pelo CNPq, contemplada com bolsa de pesquisa por meio do Edital Universal MCTI/CNPq 14/2014, com vigência até 2017.

${ }^{2}$ Recebido: 12-09-2016/ Aceito: 08-12-2016/ Publicado on-line: 19-01-2017.

${ }^{3}$ Jorge Luiz Viesenteiner é Professor Adjunto da Universidade Federal do Espírito Santo, Vitória, ES, Brasil.

${ }^{4}$ As obras de Nietzsche são citadas conforme a edição crítica: NIETZSCHE, F. Sämtliche Werke. Cont.
} 
positivos da filosofia de Nietzsche, especialmente no horizonte das reivindicações de objetividade moral, emerge como um dos mais intensos tema de debate. As perspectivas naturalistas na discussão anglo-americana, como Janaway (2007 e 2012), Leiter (2002 e 2009) e Schacht (2011) contribuem sensivelmente com o debate, sustentando variadas posições metaéticas na filosofia de Nietzsche - orbitando em termos gerais entre cognitivistas e não-cognitivistas -, diversas de outras que o situam no horizonte de um perfeccionismo moral como Brobjer (1995 e 2003) e Hatab (2008), bem como daquelas genealógicas/semiológicas encontradas no debate alemão, como Saar (2007), Stegmaier (2010 e 2012), van Tongeren (2012) e Müller (2014), para citar alguns participantes do debate. O debate no Brasil possui contribuições feitas por Lopes (2013) e Araldi (2013), com forte influência do debate naturalista angloamericano.

Em pesquisas anteriores, porém, venho desenvolvendo uma contribuição em torno de reivindicações normativas, a partir da passagem do conceito nietzscheano de genealogia de 1887 para a autogenealogia nos textos de 1888. Minha hipótese central no argumento autogenealógico - para além dos detalhes constitutivos do argumento - consiste em chamar atenção a duas direções capitais do argumento. Por

\footnotetext{
Kritische Studienausgabe in 15 Bänden. (KSA) Hrsg. Giorgio Colli und Mazzino Montinari. Berlin/New York: DTV \& Walter de Gruyter, 1999. Utilizo as seguintes referências e abreviações já consolidadas para os textos de Nietzsche, aos livros que cito: Para as referências de obras enviadas para publicação de Nietzsche, segue-se a abreviação do livro (HH: Humano, demasiado humano; GC: A gaia ciência; ABM: Para além de bem e mal; GM: Para genealogia da moral; CW: O caso Wagner; EH: Ecce homo), número do aforismo e referência nas obras completas KSA, com seu respectivo volume e número de página (p.ex., ABM 257; KSA 5, p. 205; EH, Crepúsculo dos ídolos 2; KSA 6, p. 355, etc.). Todas as traduções são de minha própria autoria.
} 
um lado, para o fato de que aquilo que Nietzsche operava com vistas a uma crítica à cultura por meio da pergunta pelo significado dos ideais ascéticos em Para genealogia da moral (GM), estrutura-se nos textos de 1888 com vistas para si mesmo e por meio de uma estratégia de autoencenação filosófica. A práxis genealógica de 1887 em GM, especialmente na terceira dissertação, direciona-se às principais estruturas da cultura: arte, filosofia, ciência, religião e moral. Contextualmente, essas estruturas culturais correspondem a cada um dos livros que Nietzsche escreve em 1888: O caso Wagner (CW) (arte), Crepúsculo dos ídolos (CI) (filosofia e ciência), $\mathrm{O}$ anticristo (AC) (religião), além de mostrar a si mesmo como filósofo Nietzsche, convertendo-se a si mesmo na figura de pensamento "Nietzsche", em Ecce homo (EH). Trata-se, portanto, de um prolongamento e radicalização do projeto genealógico de 1887, por meio de uma estratégia argumentativa estruturada como autoencenação filosófica. Por outro lado, consiste também em enfatizar o estatuto autorreferencial do argumento autogenealógico, no rigoroso sentido de um movimento circular parasitário de um elemento externo àquele que critica, de modo a reconhecer-se não mais imune, mas sim inserido, por uma questão de dever de honestidade, no próprio processo e no contexto que é objeto de crítica. Isso significa que o exercício crítico de Nietzsche à cultura alemã ou mesmo à moral cristã, por exemplo, é simultaneamente um exercício crítico contra si mesmo, na qualidade de partícipe desse mesmo processo e contexto, cujo resultado não é apenas a compreensão do desvelamento do "valor dos valores" daquele contexto, mas também sua autocompreensão genealógica (Autor, 2014 e 2015). O estatuto autorreferencial da autogenealogia exerce um im- 
portante papel no contexto de reivindicações de objetividade moral, tal como veremos, especialmente por garantir as condições de alternância de perspectivas valorativas, sem precisar assumir algum espaço transcendental ou apelar a algum referencial naturalista de justificação axiológica.

Essa dupla estrutura do argumento autogenealógico é crucial para entendermos a hipótese de objetividade moral, que por ora gostaria apenas de esboçar e que pode ser expressa tal como se segue. Nietzsche ocupa uma posição nãocognitivista em metaética, na medida em que o processo de formação dos nossos juízos de valor remonta ao efeito de duradouro da moralidade sobre nossos sentimentos e afetos, até serem psicologicamente incorporados por cada um de nós (cf. A 9, 14 e 16), de modo que nos está vedado qualquer acesso correspondencial dos nossos juízos com nossas crenças morais. Não há, neste caso, quaisquer reivindicações de verdade ou falsidade para os nossos juízos de valor, mas sim assentimento afetivo a certos juízos para os quais temos inclinações ou aversões, ou seja, a "história dos sentimentos morais é completamente diferente da história

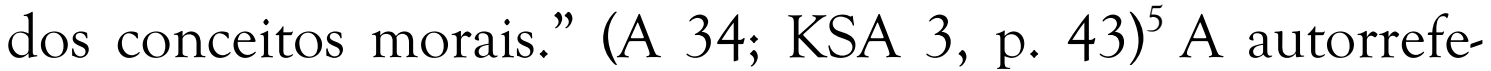

\footnotetext{
${ }^{5}$ Parto aqui da diferença básica em metaética entre cognitivismo e sua relação com crenças, e nãocognitivismo e sua relação com emoções e desejos: "Considere-se um juízo moral particular, tal como o juízo de que matar é errado. Que tipo de estado psicológico isso expressa? Alguns filósofos chamados cognitivistas pensam que um juízo moral como esse exprime uma crença. Crenças podem ser verdadeiras ou falsas: elas são aptas à veracidade ou capazes de serem assentidas em termos de verdade e falsidade. Assim, cognitivistas pensam que juízos morais são capazes de ser verdadeiros ou falsos. Por outro lado, os não-cognitivistas pensam que juízos morais exprimem estados não-cognitivos como emoções e desejos. Desejos e emoções não são aptos à veracidade." (Miller, A. Contemporary Metaethics. Cambridge: Polity Press, 2013. p. 3) Nietzsche obviamente não constrói a justificação de um juízo moral por meio da reivindicação de um argumento correspondencial, de modo que o juízo moral corresponda a crenças morais, possibilitando-o falar em juízo verdadeiro ou falso, visto que seu perspectivismo de-potencializou tais reivindicações (Cf. A 117 e GC 374). Acrescente-se ainda a tese de que um juízo de valor sobre a vida nunca pode ser Cont.
} 
rencialidade autogenealógica, porém, nos permite uma distância crítica do processo de modelamento dos nossos sentimentos e afetos morais, de modo a trazer à luz e problematizar precisamente algumas cristalizações afetivas que se tornam "pontos cegos", cujo distanciamento tem de ser capaz de exercer, para aquele que assim compreendeu, algum tipo de força normativa capaz de orientar ações posteriores. Isso implica na tese de que a formulação teórica dos nossos pontos cegos afetivamente cristalizados possuiria algum sucesso motivacional capaz de remodificar e remodelar o horizonte dos nossos sentimentos e afetos, mais ou menos como Nietzsche exprimiu essa tese pela primeira vez

verdadeiro, mas ganha estatuto e validade teórica unicamente como um sintoma: "Juízos, juízos de valor sobre a vida, pró ou contra, não podem, por fim, serem nunca verdadeiros: eles só têm valor como sintomas, são levados em consideração apenas como sintomas" (CI, O problema de Sócrates 2; KSA 6, p. 68). Isso significa que o modo pelo qual construímos um juízo de valor sobre a vida, por exemplo, remonta à nossa economia de sentimentos e afetos, portanto, um estado mental fisio-psicológico e não-cognitivo, mas que exerce um papel sobre nós determinando nossas inclinações ou aversões a algo. Não estamos em condições, conforme escreve Nietzsche, de construir uma condição de verdade de um juízo de valor. Além disso, Nietzsche assume com clareza a noção de que qualidades morais não existem no mundo, de modo a também garantir uma correspondência entre o juízo moral e essas qualidades. Trata-se aqui da forte tese do antirrealismo moral em Nietzsche, ou seja, "de que não existem absolutamente fatos morais", mas somente uma interpretação moral dos fatos (CI, Os melhoradores da humanidade 1). Neste aspecto, Nietzsche radicaliza a tese de Hume, a propósito de que todos os "juízos pelos quais distinguimos entre o bem e o mal morais" são sempre compreendidos como "percepção", portanto estados mentais, de modo que "aprovar um caráter e condenar outro são apenas duas percepções diferentes." (Hume, D. TNH. L.3, P.1, S.2, §2, p. 496). Esse caráter antirrealista das distinções morais tem como conclusão a clássica advertência humeana de que não podemos passar, inadvertidamente, de como as coisas são para como as coisas devem ser: "Em todo sistema de moral que até hoje encontrei, sempre notei que o autor segue durante algum tempo o modo comum de raciocinar, estabelecendo a existência de Deus, ou fazendo observações a respeito dos assuntos humanos, quando, de repente, surpreendo-me ao ver que, em vez das cópulas proposicionais usuais, como é e não é, não encontro uma só proposição que não esteja conectada a outra por um deve ou não deve. Essa mudança é imperceptível, porém da maior importância." (Hume, D. TNH. L.3, P.1, S.2, §27, p. 509) Registro desde já as frutíferas interfaces teóricas entre Nietzsche e Hume, e a tese anti-realista é só mais uma delas. Tal como Nietzsche, Hume também exprimiu a tese de que "não há fatos morais, mas apenas apreciações morais de fatos ordinários." (Brito, Adriano. "Naturalismo moral”. In: Torres, João C. Manual de ética. Petrópolis: Vozes, p. 352). 
em Aurora: "Nós temos de pensar diversamente, - para enfim, talvez bem mais tarde, ainda alcançar algo a mais: sentir diferentemente." (A 103; KSA 3, p. 92) Ou seja: uma posição metaética não-cognitivista, mas com pretensões de objetividade moral.

\section{Estruturação do Problema}

Uma característica determinante da práxis genealógica e autogenealógica de Nietzsche é justamente pôr em questão aquilo que nos "valores" é "tido como dado, como efetivo, como além de todo questionamento", cuja práxis é denominada por Nietzsche como "crítica" (GM Prefácio 6; KSA 5, p. 253). Isso significa que é impossível prescindirmos de quaisquer comprometimentos morais ao realizarmos uma crítica moral, de modo a assumirmos que carregamos certos preconceitos que não conseguimos, prima facie, formulá-los com clareza. Trata-se da consideração nietzscheana da "moral" como a "autêntica Circe dos filósofos" (A Prefácio 3; KSA 3, p. 13), cuja tarefa genealógica é então enxergar a moral "como problema", a fim de não apenas tocar no problema da sua origem revelando-a como "erro", mas também de questionar seu próprio "valor" (GC 345; KSA 3, p. 579). ${ }^{6}$

\footnotetext{
${ }^{6}$ Nietzsche estava consciente de que a investigação genealógica da moral, ao desvelar sua origem, não nos autoriza a extrair um juízo de valor sobre essa mesma origem, bem como sobre a moral que daí se desenvolveu, sob pena de invalidar a própria estratégia genealógica ao reivindicar uma instância teórica que definitivamente não é possível demonstrar como superior ou válida, fazendo seu argumento desembocar em uma falácia genética. No mesmo aforismo 345 de A gaia ciência Nietzsche registra atentamente a consciência desse problema, afastando de alguma maneira sua práxis genealógica da falácia genética: "Uma moral poderia ter crescido propriamente a partir de um erro: mesmo com essa concepção o problema de seu valor não estaria nem sequer tocado." (GC 345; KSA 3, p. 597) Por isso não se trata de reivindicar validade ao argumento genealógico pela mera análise da origem, mas sobretudo pela investigação do "valor dos valores". Sobre o tema Cont.
} 
Assim, grosso modo, o problema de partida é que se todas as abordagens morais estão comprometidas com pressupostos morais que não são problematizados, mas sim tomados como "dados", a crítica nietzscheana à moral igualmente não poderia estar imune a tais pressupostos, sob pena de reivindicar um espaço transcendental ou um lugar externo à vida mesma?

Em termos específicos, Nietzsche tem em vista duas grandes tradições morais da filosofia moderna: a tradição moral inglesa, especialmente vinculada aos utilitaristas, bem como a tradição moral alemã, cujo principal interlocutor é Kant. $^{8}$ Segundo Nietzsche, ambas não conseguem problematizar a moral, mas apenas descrevê-la ou fundamentá-la, tomando-a como "dada", ou seja, estão de tal modo comprometidas e seduzidas com os pressupostos de uma moral cristalizada que não conseguem sequer enxergar essa própria moral como problema. Três textos do período de 1886 e 1887 exprimem esse posicionamento de Nietzsche. No

\footnotetext{
da falácia genética em Nietzsche, cf. Conway, D. "Genealogy and Critcal Method”. In: Schacht, R. Nietzsche, Genealogy, Morality. Berkeley/Los Angeles/ London: University California Press, 1994. pp. 325-331, e Finken, B. "Nietzsche versus the Genetic Fallacy". In: Journal of Nietzsche Studies, v. 43, n. 2 (Autumn 2012), pp. 305-315.

${ }^{7}$ No Crepúsculo dos ídolos Nietzsche registra com clareza essa tese, que por sua vez indica também o quão consciente ele estava da necessidade de uma crítica imanente do valor dos valores: "Se é necessário, se é um fragmento de destino, pertence-se ao todo, se está no todo, - não existe nada que pudesse julgar, medir, comparar, condenar nosso ser, pois isso significaria julgar, medir, comparar, condenar o todo [...]. Mas nada existe fora do todo!" (CI, Os quatro grandes erros 8; KSA 6, p. 96) Um debate importante sobre o distanciamento de Nietzsche de uma posição transcendental pode ser encontrado em Conway, D. op.cit., 325-331, e mais recentemente no texto de Anderson, R. "What is a Nietzschean Self?". In: Janaway, C.; Robertson, S. (orgs.) Nietzsche, Naturalism and Normativity. Oxford: Oxford University Press, 2012, especialmente nas pp. 204-208. Além disso, o artigo de Richardson, J. "Nietzsche and Transcendental Argument". In: Kriterion 128, v.1 (2013), pp. 287-305, ao contrário, explora justamente o uso nietzscheano do clássico argumento transcendental kantiano, nas esferas teóricas, práticas e estéticas.

${ }^{8}$ Cf. Hatab, Lawrence J. On the Genealogy of Morality. Cambridge: Cambridge University Press, 2008, especialmente o capítulo "Nietzsche and modern moral theories" (pp. 208-217).
} 
aforismo 186 de Para além de bem e mal (ABM), embrionário ao projeto de Para genealogia da moral de 1887, Nietzsche explica esse problema em relação a Kant: "Os filósofos todos exigiram de si [...] algo mais elevado, mais exigente e mais festivo ao dedicarem-se à moral como ciência: eles quiseram a fundamentação da moral, - e cada filósofo acreditou até agora ter fundamentado a moral; a moral mesma, no entanto, era considerada como 'dada'." (ABM 186; KSA 5, p. 105s. $)^{9}$ No aforismo 345 de A gaia ciência (GC) ele se dirige aos ingleses, apontando o mesmo problema da sedução com a moral dominante: "Ganha-se pouco com esses historiadores da moral (precisamente os ingleses); eles mesmos ainda estão ingenuamente sob o comando de uma determinada moral e, sem que o saibam, entregam-se a ela como escudeiros e seguidores; mais ou menos como aquela ainda franca superstição popular da Europa cristã, de que o mais característico da ação moral seria a abnegação, a autonegação, o sacrificar-se a si mesmo ou empatia, a compaixão.” (GC 345; KSA 3, p. 578. Cf. também GM I 1)

Reconstruir o programa genealógico de investigação sobre a construção dos nossos sentimentos morais, de modo a atuarem como juízos de valor capazes de remodelar nova-

\footnotetext{
${ }^{9}$ Vale a pena lembrar o trecho do "Prefácio" à Fundamentação da metafísica dos costumes, onde se lê que Kant efetivamente considera como dado aquilo que no fundo ele próprio teria de fundamentar: "[...] pois, que tenha de haver semelhante Filosofia fica claro por si mesmo a partir da ideia comum do dever e das leis morais." (Kant, I. Fundamentação da metafísica dos costumes. Trad. Guido A de Almeida. São Paulo: Discurso Editorial/ Barcarolla, 2009, p. 71). Não é nada autoevidente que uma lei moral que implique validade universal seja efetivamente uma "ideia comum". Justamente essa consideração autoevidente é que exprime a sedução moral ou seus compromissos de ponto de partida que o próprio Kant não consegue problematizar. Esse tipo de "fundamentação" que já é problemática na maneira que Kant exprime logo no "Prefácio" - pois toma como dado o que deveria fundamentar -, significa precisamente aquela "crença na moral dominante", bem como uma "espécie de omissão de que fosse lícito formular essa moral como problema" (ABM 186; KSA 5, p. 106).
} 
mente os afetos humanos até sua cristalização no interior de uma cultura é, obviamente, tarefa que não caberia nesse texto. ${ }^{10}$ Decisivo para minha hipótese, porém, é a tese nietzscheana de que nossas ações são psicologicamente motivadas por um estado mental não-cognitivo, especialmente porque nossos assentimentos de inclinações e aversões são mobilizados por meio de um sentimento de empatia em relação a algo que, por isso, nos faz denominar esse algo de vício ou virtude. Em termos gerais, precisamente porque sentimos de uma determinada maneira, então temos inclinação ou aversão para também ajuizar axiologicamente algo como virtude ou vício ${ }^{11}$, cujos juízos e valorações novamente atuam remodelando e cristalizando-se em nossos sentimentos e afetos. Chamo atenção para o caráter circular da relação entre sentimentos morais e conceitos morais: sentimos aversão ou inclinação em relação a algo como motivação moral, cujos juízos e valorações formadas são retransmitidos novamente sob a forma de sentimentos, isto é, se somos psicologicamente motivados a agir por conta

\footnotetext{
${ }^{10}$ Essa reconstrução, como se sabe, pode ao menos ser indicada com seu início em Humano, demasiado humano $(\mathrm{HH})$, notadamente o "Capítulo segundo" intitulado "Contribuição à história dos sentimentos morais", passando pelo "Livro II" de Aurora (A) e alguns aforismos do "Livro I" tais como o 9, 14 e 16, até seu paralelo teórico em Para além de bem e mal, especialmente o "Capítulo quinto" denominado de "Contribuição à história natural da moral": etapas fundamentais na compreensão teórica do programa genealógico levado a termo em Para genealogia da moral. Para uma detalhada reconstrução, especialmente do paralelo entre Humano [...] e Para além de bem e mal, cf. Tongeren, P. A moral da crítica de Nietzsche à moral. Curitiba: Champagnat, 2012, principalmente as pp. 83-131. Além disso, extremamente elucidativo é o livro de Stegmaier, W. Nietzsches „Genealogie der Moral“. Darmstadt: WBG, 2010, com especial atenção às pp. 26-53.

${ }^{11}$ Impossível deixar de enfatizar a forte conexão da tese anti-realista de valores de Nietzsche com a de Hume, bem como suas adesões a um não-cognitivismo moral, especialmente se lemos o seguinte trecho do Tratado da natureza humana: "O próprio sentimento constitui nosso elogio ou admiração. Não vamos além disso, nem investigamos a causa da satisfação. Não inferimos que um caráter é virtuoso porque nos agrada; ao sentirmos que nos agrada dessa maneira particular, nós de fato sentimos que é virtuoso." (Hume, D. TNH. L.3, P.1, S2, §3, P. 510s.)
} 
dos nossos sentimentos e afetos de inclinação ou aversão a algo, nossos juízos e valorações igualmente remodelam esses afetos - tão logo entram em contato com um contexto cultural estruturado -, precisamente porque são retransmitidos novamente na forma de sentimentos. ${ }^{12} \mathrm{O}$ aforismo 34 de Aurora exemplifica as linhas gerais dessa relação:

Sentimentos morais e conceitos morais. Sem dúvida que os sentimentos morais são transmitidos de tal modo que as crianças percebem nos adultos fortes inclinações e aversões em relação a determinadas ações, e, como macacos natos, imitam essas inclinações e aversões; por uma questão de decência, em suas vidas posteriores, quando se encontram plenas desses afetos aprendidos e bem exercitados, inserem um Por quê? adicional, uma espécie de fundamentação para tais inclinações e aversões. Essas "fundamentações", porém, não têm nada a ver com a origem e nem com o grau de sentimento: cada um de nós simplesmente adapta-se à regra, uma vez que, como seres racionais, temos de ter razões para nosso pró e contra e, na verdade, razões apresentáveis e aceitáveis. Dessa forma, a história dos sentimentos morais é completamente diferente da história dos conceitos morais. (A 34; KSA 3, p. 43)

Dessa origem e história dos chamados sentimentos morais, gostaria de reter por enquanto o caráter não-cognitivo dos nossos estados mentais motivadores da ação. A cristalização dos preconceitos morais só é possível precisamente pelo caráter não-cognitivo dessas motivações, na medida em que "nos são hereditariamente transmitidos na forma de sentimentos (inclinações, aversões)" (A 35; KSA 3, p. 43s.), de modo que cada "impulso" é novamente "remodelados"

\footnotetext{
${ }^{12}$ Sobre esse caráter circular da relação entre sentimentos/afetos e juízos/conceitos morais, cf., dentre outros, os aforismos 19, 33, 34, 35, 38, 103, 111 e 148 de Aurora. Esse tema da circularidade foi amplamente explorado por Piazzesi, C. "Was Alles Liebe genannt wird' ('Tudo o que é chamado de amor'): FW/GC 14 como exemplo de exercício pré-genealógico." In: Cadernos Nietzsche 27 (2010), pp. 73-115, especialmente a análise do aforismo 38 de Aurora, pp. 98-100.
} 
(umgestalten) por nossos juízos morais (A 38). O programa genealógico, neste caso, consiste precisamente problematizar o que se tornou evidente e cristalizado no interior desse processo de moralização dos costumes. Ao "Por quê?" ou "fundamentações para as inclinações ou aversões" de que fala o aforismo 34 de Aurora - exercício que se faz meramente para estruturarmos com alguma coerência nosso mundo moral, mas que culmina com a adaptação de cada um "à regra" - corresponde precisamente o aforismo $186 \mathrm{de}$ Para além de bem e mal, a propósito da solene tentativa dos filósofos para encontrarem uma "fundamentação da moral", cujo resultado é igualmente a adaptação à regra, uma vez que justamente essa moral não é problematizada. $\mathrm{O}$ programa genealógico, como se sabe, é apresentado por Nietzsche no aforismo 6 do "Prefácio" da Genealogia, e consiste então em ver como problema aquilo que se tornou sedimentado ou cristalizado no interior de uma cultura: "Exprimamos então essa nova exigência: necessitamos de uma crítica dos valores morais, o próprio valor desses valores terá de ser colocado em questão [...]. Tomava-se o valor desses 'valores' como dado, com efetivo, como além de todo questionamento" (GM Prefácio 6; KSA 5, p. 253). Com isso, compreendemos melhor e retornamos ao nosso problema de partida: se ingleses e alemães estão engajados com pressupostos morais 'dados' e cristalizados, então, com aquele que critica também não pode ser diferente, ou seja, Nietzsche tem de reconhecer que também carrega tais cristalizações morais que orientam sua crítica (Tongeren 2012). ${ }^{13} \mathrm{~A}$ au-

\footnotetext{
${ }^{13}$ Partimos aqui do conceito de genealogia em seu registro crítico (Cf. Saar 2007; Stegmaier 2010) e não como história de surgimento (Entstehungsgeschichte). Nesse momento, trata-se de compreenCont.
} 
torreferencialidade do argumento autogenealógico tem de dar conta de problematizar as cristalizações, na medida em que consegue com algum sucesso um mecanismo de alternância de perspectiva - uma "perspectividade" -, a fim de enxergar seu próprio 'ponto cego'.

\section{AUTORREFERENCIALIDADE AUTOGENEALÓGICA E REIVINDICAÇÃO DE OBJETIVIDADE MORAL}

Nessa terceira e última parte do artigo pretendo esboçar as possibilidades de objetividade moral, servindo-me da fecundidade do conceito de autorreferencialidade constitutivo do argumento autogenealógico, isto é, se é possível resultar do procedimento autogenealógico algum juízo de valor que tenha força normativa capaz de motivar nossas ações posteriores.

Gostaria de dizer logo de início que por objetividade moral não se deve compreender, repito, nenhum comprometimento de Nietzsche com uma posição cognitivista da moral, de modo a se falar em verdade ou falsidade do juízo moral relativamente à correspondência dos nossos juízos com nossas crenças (cf. explicação da nota 3 desse artigo). Sem dúvida que versões cognitivistas são coerentes com a filosofia de Nietzsche, especialmente aquelas oriundas da as-

\footnotetext{
der então genealogia em sua dimensão metaética, na medida em que não importa apenas uma descrição da função e aplicabilidade em diversos contextos espaço-temporais de bem e mal, justo e injusto, correto e incorreto, traços de caráter e importância de virtudes, etc., numa espécie de descrição historicizada dos valores, mas sobretudo uma crítica do "valor desses valores". Para utilizar a diferença que J. Mackie emprega para caracterizar a distinção entre ética e metaética, a genealogia seria uma metaética por tratar de "questões de segunda ordem", em confrontação com o discurso ético de "primeira ordem". Mackie, J. Ethics: Inventing Right and Wrong. London: Penguin Books, 1990. p. 9.
} 
sim denominada “teoria do erro" de John Mackie ${ }^{14}$, e que exploram a partir daí a fecundidade do ficcionalismo moral que, grosso modo, assume a tese de que juízos morais são ficções sem um valor cognitivo específico, mas que são assentidas e partilhadas por conta do valor prático que possuem para a organização do nosso mundo moral. $\mathrm{O}$ material que sustenta essa tese é vasto e desde Humano, demasiado humano I também é bem frequente a associação feita por Nietzsche entre juízos de valor e o erro/falsidade desses juízos, com o caráter pragmático de assentimento aos juízos errôneos. ${ }^{15} \mathrm{O}$ mais curioso é que a tese ficcionalista assume

\footnotetext{
${ }^{14}$ Para um rápido esclarecimento, a teoria do erro em metaética é a tese de que a reivindicação de quaisquer sentenças morais de um discurso é "sistematicamente e uniformemente falsa". O argumento é amplamente devedor da noção de que não temos absolutamente nenhum acesso cognitivo a qualidades morais pertencentes ao mundo e, mesmo que tivéssemos, precisaríamos ter uma "especial faculdade de percepção ou intuição moral radicalmente diferente das nossas maneiras de conhecimento de qualquer coisa", algo que certamente tem de soar "estranho" (Mackie, J. op.cit., p. 38). Isso significa que não é possível conjugar, na teoria do erro, as exigências conceituais/epistemológicas da condição de verdade correspondencial de juízos morais, com as exigências ontológicas, pois qualidades morais não são propriedades ontológicas do mundo, e mesmo que fossem, não teríamos acesso epistêmico a tais propriedades morais. As exigências conceituais seriam, por um lado, aquelas de que "sentenças morais possuem condições de verdade, cuja obtenção exigiria a existência de fatos prescritivos objetiva e categoricamente", bem como a de que "juízos morais exprimem crenças, cuja verdade exigiria a existência de fatos prescritivos objetiva e categoricamente". A exigência ontológica, por outro lado, recusa intransigentemente uma versão de realismo moral com a proposição de que "não existe fatos prescritivos objetiva e categoricamente" (Miller, op.cit., p. 105). Assim, se não temos quaisquer possibilidades de acesso a "fatos prescritivos objetiva e categoricamente", e a existência de alguma faculdade que nos garantiria tal acesso tem de soar "estranho", quaisquer juízos morais que declaramos será falso.

${ }^{15}$ Para traçar uma linha genérica dessas referências a fim de servir apenas de um rápido indicativo, sem qualquer pretensão de esgotar a fecundidade dessa análise que já remonta à recepção neokantiana feita por Nietzsche, passando pelas análises de $\mathrm{H}$. Vaihinger, até os debates mais atuais que exploram a relação desse ficcionalismo no debate em metaética, cf. HH 29, 32, 33, 39; A 103, 148; GC 107, 299, 301; ABM Prefácio, 4 e CI, Os melhoradores da humanidade 1. No Brasil, trabalhos de Rogério Lopes - "Ceticismo e vida contemplativa em Nietzsche" (Tese de doutorado) - Fernando C Mattos - "Nietzsche: Perspectivismo e Democracia" - e Ricardo B Dalla Vecchia "O(s) perspectivismo(s) de Nietzsche" (Tese de doutorado) - fornecem material de compreensão da recepção kantiana e seus impactos no ficcionalismo. Enfatize-se que essa despretensiosa e aleatória indicação de aforismos que fiz apenas assume o papel de registrar a fecundidade do ficcionalismo moral em Nietzsche. Para indicar algumas leituras do ficcionalismo no debate atual em metaética, cf. Blackburn, S. "Perspectives, Fictions, Errors, Play". In: Leiter, B.; Sinhababu, N. Cont.
} 
a posição de "inventarmos uma ficção de que as coisas tem de ser feitas de tal maneira", mesmo sentindo que elas não são. ${ }^{16}$

Por objetividade moral compreendo antes o procedimento teórico de distanciamento dos nossos afetos e sentimentos garantido pela autorreferencialidade autogenealógica, que cria tanto uma cognoscibilidade mínima dos nossos preconceitos cristalizados, como também a condição de possibilidade de alternância de perspectivas em uma crítica imanente dos valores morais, cujo resultado é menos a veracidade objetiva do que se exprime, mas muito mais o "controle sobre o conteúdo moral"17 dos nossos juízos de valor que, ao serem formulados em termos teóricos, teria de ter algum tipo de força normativa para reorientar e reorganizar a criação de novos valores e novas ações. Esse tipo de reivindicação de objetividade moral no debate nãocognitivista - que como escreveu S. Blackburn, "deveria nos prevenir de querer bater na porta dos visionários" $" 18$ - flerta com uma concepção "deflacionista" da verdade, cuja "ideia básica" compartilhada entre as diversas versões do deflacio-

\footnotetext{
(orgs.) Nietzsche and Morality. Oxford: Oxford University Press, 2012, pp. 281-296; Hussain, N. "Honest Illusion: Valuing for Nietzsche's Free Spirits". In: Leiter, B.; Sinhababu, N. (orgs.), op.cit., pp. 157-191; Clarck, M.; Dudrick, D. "Nietzsche and Moral Objectivity: the Development of Nietzsche's Metaethics". In: Leiter, B.; Sinhababu, N. (orgs.), op.cit., pp. 192-226; Leiter, B. "Nietzsche's Metaethics: Against the Privilege Reading's. In: European Journal of Philosophy 8 (2000), pp. 277-297; Thomas, A. "Nietzsche and Moral Fictionalism". In: Janaway, C.; Robertson, S. (orgs.). Nietzsche, Naturalism and Normativity. Oxford: Oxford University Press, 2012, pp. 133-159.

${ }^{16}$ Cf. Blackburn, S. op.cit., p. 285s. O mesmo argumento é mencionado por Hussain com sua tese da "ilusão honesta", ou seja, um sujeito "S" valora "X" considerando "X" valorável, mesmo sabendo que, de fato, "X" não é valorável em si mesmo. (Hussain, N. op.cit., p. 166)

${ }^{17}$ Schroeder, M. Noncognitivism in Ethics. London/New York: Routledge, 2010. p. 163. Todo capítulo 8 do livro aborda a relação entre "verdade" e "objetividade" de teorias não-cognitivistas em metaética (pp. 151-171) (o grifo é meu).

${ }^{18}$ S. Blackburn, op.cit., p. 285.
} 
nismo em metaética é aquela que sustenta uma verdade/validade do juízo moral em detrimento da correspondência do juízo com nossas crenças, mas em proveito da concordância ou desacordo das nossas atitudes conativas em relação a algo. Assim, “grosso modo, 'verdadeiro' é uma palavra que usamos para concordar com alguma coisa, e 'falso' é uma palavra que usamos para discordar de algo."19 No caso de Nietzsche, uma tal objetividade significa colocar a pergunta, como já fez há algum tempo B. Leiter, se ao "oferecer uma reelaboração da moralidade Nietzsche faz algo a mais do que simplesmente dar sua idiossincrática opinião, a partir das suas idiossincráticas perspectivas valorativas." (Leiter 2002, p. 137) Considero importante a pergunta, mas não satisfatória a solução naturalista de B. Leiter para aquilo que ele abreviou de MPS (moral em sentido pejorativo). A meu ver, é possível levarmos a termo a tese não-cognitivista da construção dos nossos juízos de valor, mas com a reivindicação de uma objetividade moral tal como definimos acima.

Retornemos então ao nosso problema de partida. Deci-

\footnotetext{
${ }^{19}$ Schroeder, M. op.cit., p. 154. Como se vê, essa concepção deflacionista da verdade implica em uma separação entre uso e significado de sentenças morais. Trata-se da concepção segundo a qual nossos juízos morais "exprimem" nosso assentimento em relação a certas atitudes conativas de um determinado jogo de linguagem, e não um "comprometimento com a verdade do que estamos dizendo", relativamente às nossas crenças (cf. Mendonça, W. "Questões metaéticas". In: Torres, João C. (org.) Manual de ética. Petrópolis: Vozes, pp. 153-173, aqui citado na p. 170). O primeiro capítulo do livro de J. Mackie, além disso, traz algumas concepções de reivindicação de objetividade que, para minha hipótese, são bem interessantes. $O$ texto de Miller, A. op.cit., p. 108, traz uma lista resumida dessas noções de objetividade que, particularmente, interessam-me as seguintes posições: "Falar em reivindicação objetiva é dizer que algo pode ser objeto de conhecimento, [...] que pode ser percebido, pode ser reconhecido [...], que algo pode ser tornado consciente". Em cada uma delas exprime-se algum tido de cognoscibilidade autorreferencial nos nossos preconceitos cristalizados que, ao ascender à consciência como problema, podem ser reconhecidos efetivamente como tal, de modo a ganhar, justamente por isso, alguma objetividade deflacionada que seja capaz de ter força normativa.
} 
sivo aqui é que há uma espécie de "ponto cego" do crítico moral que ele não consegue absolutamente enxergar, a saber, a sua própria perspectiva. Nós já sempre estamos inseridos, por um lado, em uma determinada situação a partir da qual exprimimos nossos juízos ou operamos com nossa crítica ao contexto moral em que nos situamos, mas como também sabemos, por outro lado, não conseguimos enxergar precisamente os comprometimentos cristalizados nos nossos próprios juízos de valor. Trata-se de uma questão básica elaborada por Nietzsche em seu perspectivismo e que consiste em reconhecermos que possuímos um limite de horizontes ${ }^{20}$, bem como que nunca estamos absolutamente conscientes do pathos próprio da vida enquanto nela nós estamos. ${ }^{21}$ Nietzsche estava plenamente consciente desse problema, tal como registrou no famoso aforismo 374 de A gaia ciência, intitulado "Nosso novo infinito": "Quão longe alcança o caráter perspectivista da existência [...] isso não pode ser resolvido, como é usual, nem pela mais dedicada e penosa análise e autoexame do intelecto: pois nessa análise o intelecto humano só consegue enxergar a si próprio sob suas formas perspectivista e apenas nelas. Não conseguimos enxergar a nossa própria esquina." (KSA 3, p. 626) Por dever de honestidade, como vimos, Nietzsche não pode reivindicar uma posição imune a tais cristalizações morais, supostamente capaz de enxergar sua própria esquina, de

\footnotetext{
${ }^{20}$ Em Aurora Nietzsche escreveu um aforismo intitulado "Na prisão" que talvez ilustre essa noção de horizonte: "Minha visão, independente se seja forte ou fraca, enxerga apenas a uma certa distância, e nesta margem eu articulo e vivo, esta linha de horizonte é meu destino mais próximo, grande ou pequeno, no qual posso escapar." (A 117; KSA 3, p. 110)

${ }^{21}$ Cf. GC 317: "Apenas raramente nos tornamos conscientes do autêntico pathos de cada período da vida, enquanto nele estamos" (KSA 3, p. 549).
} 
modo que ele tem de empregar contra si o mesmo instrumental teórico direcionado na crítica às tradições alemã e inglesa da moral, ao levar a cabo seu programa genealógico. Do contrário, como se diz, Nietzsche estaria reinserindo pela porta dos fundos o que tentou expulsar pela porta da frente. Assim, ele tem de fazer voltar contra si o seu próprio argumento em um movimento agora autogenealógico, reconhecendo que possui igualmente inclinações e aversões cristalizadas sob a forma de preconceitos não formulados bem como motivações psicologicamente incorporadas, renunciando precisamente ocupar uma "posição fora da vida”, tal como escreve no Crepúsculo dos ídolos (CI, Moral como contranatureza 5; KSA 6, p. 86) Nossas inclinações e aversões são, como vimos, estados mentais não-cognitivos por meio dos quais tanto exprimimos nossos juízos de valor, quanto também tais juízos remodelam nossos sentimentos e afetos. Esse processo nos torna "devotos" justamente das cristalizações que, por serem estados mentais não-cognitivos, não são formuladas como problema. Se o programa genealógico tem de pôr em questão o que se tornou autoevidente no interior desse processo, o programa autogenealógico tem de fazer o próprio Nietzsche reconhecer que ele também é um "devoto" (GC 344). Além disso, a autogenealogia tem de explicar a noção de "perspectividade"22, ou a capacidade de alternância de perspectivas no in-

\footnotetext{
${ }^{22}$ Para uma compreensão detalhada do termo perspectividade ou alternância de perspectivas, cf. o recém publicado livro de W. Stegmaier Orientierung im Nihilismus - Luhmann meets Nietzsche. Berlin/Boston: de Gruyter, 2016, pp. 60-92. Logo na p. 60 "perspectividade" é definida como a "possibilidade de 'enxergar algo', estando ligado a determinado ponto de vista ou posição, bem como delimitado por meio de um 'horizonte'." A possibilidade de alternância de perspectiva, porém, tem de ocorrer no interior da própria situação, de modo a poder enxergar sua própria perspectiva na perspectiva observada, e por meio da própria perspectiva observada (p. 61).
} 
terior de uma mesma situação, a fim de que o crítico, autorreferencialmente, possa não apenas enxergar e compreender o contexto em que está inserido, ou seja, a perspectiva que observa, mas também alternar sua posição e enxergar, retrospectivamente e por meio da perspectiva observada, sua própria perspectiva, sua própria "esquina" 23

A meu ver, essa perspectividade foi registrada por $\mathrm{Ni}$ etzsche, textualmente, desde Aurora. Emprego aqui a expressão perspectividade, por se tratar daquele processo de alternância de perspectivas, e não uma preocupação com o conceito mesmo de perspectivismo. A perspectividade é parasitária de algum elemento externo ela, por meio do qual não apenas compreendemos aquilo que enxergamos ou investigamos, mas principalmente a nós mesmos. $\mathrm{O}$ aforismo 118 de Aurora elabora a dinâmica dessa perspectividade: "O que compreendemos do nosso próximo a não ser suas fronteiras, quer dizer, aquilo com o que ele marca e igualmente imprime em nós e sobre nós? Nada compreendemos dele a não ser as transformações em nós, às quais ele é causa" (A 118; KSA 3, p. 111). ${ }^{24}$ Enxergar a própria perspectiva, ou a com-

\footnotetext{
${ }^{23}$ O texto de Simon Blackburn "Perspectives, Fictions, Errors, Play" considera atentamente uma noção forte de perspectividade. Ao explorar a clássica metáfora visual, S. Blackburn separa dois elementos diferentes na aplicação da metáfora: "o primeiro elemento é aquele já mencionado de que podemos alternar perspectivas visuais, e assim o fazemos com facilidade e voluntariamente. $\mathrm{O}$ outro é que podemos sintetizar as diferentes perspectivas como resultado." (Blackburn, S. op.cit., p. 283) Minha única objeção é que não é tão óbvio assim compreender a possibilidade de alternância de perspectiva, de modo que antes de toma-la como possibilidade dada, parece-me antes importante explicar como se dá a alternância.

${ }^{24}$ Em um apontamento póstumo preparatório a esse aforismo, Nachlass Herbst 1880 6[419], KSA 9, p. 305, Nietzsche também escreveu: "Não conhecemos outra coisa de um homem a não ser a inibição e limitação que ele exerce sobre nós, ou seja, como impressão na cera de nosso ser. Nós sempre conhecemos apenas nós mesmos em uma determinada possibilidade de transformação; muitos homens não atuam sobre nós, pois nesse caso nossa cera é demasiado dura ou mole. Por fim, conhecemos as possibilidades de deslocamento da nossa estrutura, e nada além."
} 
preensão de nós mesmos, as "transformações em nós” pressupõe uma relação parasitária com um elemento externo, uma espécie de "satélite", como escreve Nietzsche nesse aforismo, por meio do qual enxergamos retrospectivamente a nós próprios.

Ora, essa estrutura é típica do argumento autogenealógico, cuja característica é a autorreferencialidade. $\bigcirc$ programa genealógico e, sobretudo, o programa crítico autogenealógico é parasitário do interlocutor que ele pretende suplantar, isto é, enxergamos o 'ponto cego' da própria perspectiva, na medida em que dependemos do interlocutor externo, por meio do qual o crítico enxerga não somente a perspectiva que observa, mas também enxerga a si naquilo que critica. Insisto na expressão "parasita" tanto no programa genealógico, quanto no autogenealógico, e valho-me aqui não apenas da fecundidade que a metáfora possui em termos sociais e filosóficos ${ }^{25}$, quanto também na filosofia de Nietzsche. ${ }^{26}$ Assim, ao criticar o cris-

\footnotetext{
${ }^{25}$ Sobre uma abordagem filosófica da metáfora "parasita" e as possibilidades de perspectividade nas relações cotidianas, cf. Serres, M. Der Parasit. Frankfurt am Main: Suhrkamp, 1987.

${ }^{26}$ A expressão foi emprega por D. Conway em seu texto "Genealogy and Critical Method", in: Schacht, R. op.cit., p. 324s. O contexto de uso da expressão é de que para se ter "acesso aos sentidos dos fenômenos históricos sob investigação, a genealogia nietzscheana habita, parasitariamente, as interpretações dominantes daquele fenômeno. [...] Pelo fato de que as interpretações genealógicas de Nietzsche são logicamente dependentes das interpretações que pretendem suplantar, elas são inteiramente parasitas e não podem existir independentemente. [...] Qual seja o grau de validade que uma genealogia adquire, ela é inteiramente relativa à interpretação que ela desacredita [...]: a confiança de Nietzsche na genealogia reflete sua convicção de que todas as vitórias hermenêuticas são relativas ao contexto específico do combate." Sem dúvida que Nietzsche não reivindica um estatuto privilegiado à sua genealogia. Como vimos, trata-se antes de, parasitariamente, des-referencializar aquilo que se tornou autoevidente no interior dos fenômenos morais. Isso significa que a práxis autogenealógica possui um apelo performático tanto sobre o genealogista, quanto sobre seus leitores. O final do texto de D. Conway traz a hipótese de que a "mais consistente (se não a mais libertadora) leitura da Genealogia exigiria de nós tratar a descrição de Nietzsche do sacerdote ascético - um 'médico' que é ele próprio doente - como tendo um estatuto autorreferencial" (p. 331). A meu ver, essa hipótese do apelo autorreferencial do programa geCont.
} 
tianismo, p.ex., Nietzsche tem de reconhecer que critica a si mesmo como bem-comportado filho de pastor; sua confrontação sistemática contra os alemães, com inúmeras tentativas de patologização dos alemães e da sua cultura, exprime um efetivo espelhamento da sua própria patologia alemã, ou seja, se Nietzsche constrói tais patologizações em relação aos alemães, no fundo ele patologiza, negativamente, a si próprio; sua oposição a Wagner como decadente significa, no fundo, que tem de enxergar a si mesmo como decadente, enquanto propagandista da causa wagneriana; ou ainda, em termos gerais, o problema de Nietzsche com os alemães tem de ser entendido como um problema consigo mesmo. ${ }^{27}$ A crítica autogenealógica, portanto, é imanente à situação em que se encontra, no rigoroso sentido de que é dependente afetivamente das perspectivas que confronta; por isso mesmo, porém, é parasitária do interlocutor por meio do qual o crítico compreende não apenas o objeto criticado, mas simultaneamente a si mesmo. Ao enxergar a própria perspectiva por meio da dependência afetiva do interlocutor, mas com distância crítica, cria-se as condições mínimas de cognoscibilidade dos afetos cristalizados sob a forma de preconceito. In suma: um movimento circular que

\footnotetext{
nealógico encontra um eco adequado com o programa autogenealógico, no rigoroso sentido do texto de M. Saar, Genealogie als Kritik. Geschichte und Theorie des Subjekts nach Nietzsche und Foucault. Frankfurt/New York: Campus Verlag, 2007, especialmente o capítulo 7, ali onde o autor escreve sobre o caráter indutor da genealogia para um "processo de autorreflexão, que direciona as pessoas a se confrontarem consigo mesmas e com suas convicções, bem como com os ordenamentos e comportamentos próprios e, com isso, a confrontação com as instituições e identidades.” (p. 343). A estrutura performática da genealogia, que força o leitor a reconhecer-se inserido no mesmo processo também criticado, é explicada na terceira parte do terceiro capítulo (pp. 130-141).

${ }^{27} \mathrm{Um}$ detalhamento dessa circularidade autorreferencial foi elaborada por Rupschus, A. Nietzsches Problem mit den Deutschen. Wagners Deutschtum und Nietzsches Philosophie. Berlin/Boston: Walter de Gruyter, 2013, especialmente o capítulo 3 intitulado "O problema de Nietzsche com os alemães como problema consigo mesmo" (pp. 74-148).
} 
justifica a fecundidade da categoria de autorreferencialidade, pois permite ao crítico enxergar o que nele também é "dado", seu 'ponto cego'. ${ }^{28}$

Chamo atenção a um aspecto importante da autorreferencialidade que exprime o sentido da objetividade que mencionei acima, a saber, a distância crítica em relação aos próprios afetos e sentimentos, garantidos pela alternância de perspectiva, e que nos permite elaborar um mínimo de cognoscibilidade - por meio da dependência parasitária da perspectiva observada -, sobre nosso próprio ponto cego. Isso não significa apropriação da perspectiva alheia, no sentido da formulação correspondencial da verdade que se exprime, mas antes um controle maior do nosso próprio ponto cego por meio da perspectiva alheia. Provavelmente o famoso aforismo 12 da Terceira Dissertação de Para genealogia da moral exprima um pouco dessa noção de objetividade:

Não sejamos afinal, como homens do conhecimento, ingratos para com tais resolutas inversões de perspectivas e valorações corriqueiras, com as quais o espírito enfureceu-se consigo mesmo por demasiado tempo, de maneira aparentemente fervorosa e inútil: enxergar dessa maneira diferente, querer enxergar diferente é um grande cultivo e preparação do intelecto para sua doravante "objetividade" -, que não é entendida como "observação desinteressada" [...], mas como capacidade de manter sob controle seu pró e seu contra, podendo dispor deles: de modo que saiba tornar útil para o conhecimento precisamente a diversidade de perspectivas e de afetos de interpretação. [...] Existe apenas um enxergar perspectivo, apenas um "conhecer" perspectivo; e quanto mais afetos deixarmos falar sobre uma

\footnotetext{
${ }^{28} \mathrm{O}$ aforismo 324 "Miscelânea de opiniões e sentenças" intitulado "Estrangeirices" fornece um bom indicativo do experimento que Nietzsche faz com um estrangeiro que viaja pela Alemanha, sendo capaz de observar variados graus de diferença e, com isso, relativizar a si mesmo em relação às pessoas e contextos. Assim, ao falar com seus conterrâneos, Nietzsche encena a si mesmo como "estrangeiro" falando, no fundo, consigo mesmo.
} 
coisa, quanto mais olhos, olhares diversos soubermos lançar para essa mesma coisa, tanto mais completo será nosso "conceito" dessa coisa, nossa "objetividade" dessa coisa. (GM III 12; KSA 5, p. 364s. Os grifos são meus) $)^{29}$

Nietzsche fala nesses textos continuamente de sentimentos e afetos valorativos, estados mentais não-cognitivos de transmissão e remodelamento dos nossos juízos de valor, mas simultaneamente não o impede de assumir alguma concepção deflacionada de objetividade. Precisamente por se tratar de estados não-cognitivos, Nietzsche não menciona nenhuma verdade correspondencial dos juízos perspectivos, mas sim uma "capacidade de manter sob controle" nossos "prós e contras", podendo dispor deles. ${ }^{30} \mathrm{O}$ que interessa não é a verdade correspondencial da perspectiva observada, mas um controle do conteúdo da própria perspectiva, um controle maior do nosso ponto cego e seus respectivos 'prós e contras', por meio da perspectiva observada. ${ }^{31}$

Acrescento, além disso, que essa objetividade deflacionada dos nossos 'pontos cegos', tão logo seja formulada com distância crítica mínima, está em condições de ter al-

\footnotetext{
${ }^{29}$ Cf. também ABM 211 e HH I, Prefácio 6. Ambos aforismos enfatizam novamente não a verdade sobre os juizos de valor, mas sim o controle do conteúdo de tais juízos. Já algumas vezes indiquei nas notas de rodapé a frequente aproximação entre Hume e Nietzsche. A meu ver, no Tratado Hume fornece um indicativo muito similar a essa objetividade deflacionada de como corrigir nossos sentimentos, tão logo nos fixamos em um "ponto de vista firme e geral", depois de termos tomado contato com a diversidade de outros pontos de vista particulares. Cf. Hume, D. TNH, L.3, P.3, S.1, p. 621.

${ }^{30}$ Sobre esse tema, cf. o ilustrativo texto de Constâncio, J. "A Sort of Schema of Ourselves: on Nietzsche's 'Ideal' and 'Concept' of Freedom”. In: Nietzsche-Studien 41 (2012), pp. 127-162, aqui especialmente as páginas 135 s. e 137-140.

${ }^{31}$ Com base nessa reflexividade autorreferencial, o texto de R. Lanier Anderson, "What is a Nietzschean Self?". In: Janaway, C.; Robertson, S. (orgs.) op.cit., pp. 202-235 fala de um conceito mínimo de "Self", situando sua posição entre a interpretação da psicologia moral minimalista de Bernard Williams - que ele chama de "reducionista" e "eliminacionista" - e uma posição transcendental, sustentando não apenas um Self minimalista como "tarefa" e "realização", mas também sugerindo a virtude da autonomia como detentora de uma força normativa oriunda do Self.
} 
gum apelo normativo que possa remodelar e reorganizar ações posteriores. Como vimos acima, há uma relação circular entre sentimentos e conceitos morais: agimos psicologicamente motivados por inclinações e aversões, cujos juízos de valor formados são retransmitidos novamente na forma de sentimentos e afetos. Assim, juízos de valor são estados mentais afetivos que, ao serem transmitidos, podem novamente remodelar nossos afetos. Formular nosso próprio 'ponto cego' como problema, construindo alguma objetividade sobre ele, pode nos fazer enxergar certas disposições afetivas que tenham apelo motivacional capaz de reorientar nossas ações. ${ }^{32} \mathrm{O}$ Aforismo 103 de Aurora oferece um bom indicativo do quanto uma formulação cognitiva pode remodelar estados afetivos, especialmente por meio da tese: "Nós temos de pensar diversamente, - para enfim, talvez bem mais tarde, ainda alcançar algo a mais: sentir diferentemente." (A 103; KSA 3, p. 92) Os "admiradores da objetividade" são

\footnotetext{
${ }^{32}$ Sou devedor neste caso da noção de objetividade que M. Clark e D. Dudrick elaboram no texto "Nietzsche and Moral Objectivity: the development of Nietzsche's Metaethics", in: Leiter, B. op.cit. 2012, pp. 192-226. Distancio-me, porém, da tese associada com tal objetividade, a saber, a construção de um espaço de razões capazes de justificar os próprios assentimentos, bem como que essas razões afetem as disposições de outras pessoas a "sentir e agir" a partir daquilo que reivindicou ser avaliável (cf. p. 215). Sem dúvida que razões justificadas podem atuar performaticamente sobre outros interlocutores, na medida em que afeta as disposições e sentimentos de cada um. E considero mesmo que Nietzsche leva a termo essa performatividade, tanto por meio de uma estratégia argumentativa que força o leitor a se posicionar sobre os argumentos apresentados por Nietzsche, quanto por meio de uma estratégia de encenação filosófica e de autoencenação como figura de pensamento "Nietzsche'. Essa reflexão já tive oportunidade de fazer em outros artigos. Mas isso me parece ser muito mais uma estratégia por meio da qual Nietzsche exprime suas positividades genealógicas e autogenealógicas, e menos uma estratégia de reivindicação de objetividade moral. O par autogenealogia/autorreferencialidade pode ser mas frutífero neste caso. O texto de Clarck e D. Dudrick é extremamente instrutivo no debate em metaética contemporânea e, como disse, sou devedor de um conceito de objetividade ali presente. Mas registro também dois aspectos importantes que são dignos de nota: o texto mostra a superação da noção de um Nietzsche solipsista, resgatando uma dimensão forte de dialogicidade, e também sustenta uma posição metaética nãocognitivista, mas com reivindicações de objetividade moral.
} 
aqueles "que gastaram tempo e energia na reconstrução de sentimentos", a fim de conquistar essa "objetividade" deflacionada (A 111; KSA 3, p. 100). ${ }^{33}$ Esse programa teórico de reivindicação de objetividade, a meu ver, cruza os textos de Nietzsche até Crepúsculo dos ídolos, na sua consideração da moral como "mero falar em signos, mera sintomatologia". No final do aforismo, Nietzsche escreve que para se poder "tirar vantagem" da moral é preciso antes "saber de que se trata”, isto é, problematizar com algum sucesso seus pontos cegos para cumprir a exigência de "colocar-se para além de bem e mal" (CI, Os melhoradores da humanidade 1; KSA 6, p. 98). Obviamente que essa objetividade deflacionada capaz de construir apelos motivacionais com algum sucesso não implica em convergência de juízos avaliativos. Cada juízo de valor é sempre uma perspectiva afetiva radicalmente individual que pode apelar normativamente a reorientar ações e juízos futuros também individuais, mas que exerce, no máximo, alguma performatividade afetiva sobre meus interlocutores. De qualquer modo, não me parece que $\mathrm{Ni}$ etzsche apenas exprime sua "idiossincrática opinião, a partir das suas idiossincráticas perspectivas valorativas", como desafiou B. Leiter. Ao contrário, há algum sucesso nesse tipo de objetividade normativa que vai muito além da moral no mero sentido pejorativo de exprimir idiossincrasias.

Para ilustrar o procedimento, tome-se um exemplo simples da "gentileza" (Hofflichkeit) que Nietzsche menciona inúmeras vezes, inclusive como uma das suas quatro virtu-

\footnotetext{
${ }^{33}$ A articulação entre o apelo normativo e a objetividade foi analisado por Paul van Tongeren, a partir do conceito de "probidade intelectual", em especial em Para além de bem e mal. Cf. Tongeren (2012).
} 
des cardiais, em alusão a Platão ${ }^{34}$. Se estivermos inseridos em uma situação em que o afeto da gentileza seja corriqueiro e usual, esse sentimento se torna algo "dado", nosso "ponto cego", sem que o formulemos com distância crítica. Alterando-se a situação em que nos encontramos para outra de grosseria, o crítico não apenas compreende a situação beligerante em que se encontra, mas por meio da grosseria, simultaneamente, enxerga nele o sentimento cristalizado como ponto cego e não formulado: o afeto da gentileza. A 'virtude cardeal' ascende à consciência porque o crítico é parasitário do interlocutor (no caso o contexto de grosseria), por meio do qual ele compreende melhor a si mesmo autogenealogicamente, em um movimento autorreferencial. Ao formular seu ponto cego, o afeto da gentileza ganha alguma cognoscibilidade e está em condições de reivindicar alguma força motivadora e reorganizadora de novas ações. A gentileza não estava presente na situação da grosseria, pelo menos não formulada eticamente como questão de "primeira ordem"; somente parasitária à grosseria é que o afeto da gentileza foi formulado e problematizado, reestruturando e reorientando novas ações. ${ }^{35}$

A vantagem desse argumento é que 1) ele faz jus à de-

\footnotetext{
${ }^{34}$ Nietzsche se refere às quatro virtudes cardiais de Platão - sabedoria, coragem, temperança e justiça - analisadas na República a partir de 427e. Nietzsche se refere à gentileza continuamente como uma virtude cardial em diversos lugares, como ABM 284 e A 392 e 556.

${ }^{35} \mathrm{O}$ exemplo é simples, mas pode ilustrar com alguma modéstia o programa maior autogenealógico que Nietzsche executa não mais com vistas a cultura, mas sim com vistas a si mesmo nos textos de 1888. Esse detalhamento está em curso em minha pesquisa para algumas das obras desse período, como O caso Wagner e O anticristo. Em O caso Wagner, a carta aberta escrita por Nietzsche e que serve como lente de aumento à modernidade, Nietzsche é parasitário do afeto wagneriano da décadence, por meio do qual enxerga em si mesmo o mesmo afeto. Em termos gerais, a perspectiva de realização autogenealógica é aquela em que Nietzsche não apenas se autocompreende por meio de Wagner, mas que elabora normativamente sua própria posição em relação a ele. Assim, Nietzsche não escreve apenas $\mathrm{O}$ caso Wagner, mas também Nietzsche contra Wagner.
} 
nominada "economia de princípios" (ABM 13), sem precisar lançar mão de conceitos metafísicos para fundamentar uma moral, pois se não ocupamos nenhum lugar 'fora da vida', então sempre já estamos inseridos em uma situação, assumindo todos nossos 'pontos cegos'; 2) esse argumento tem a vantagem de não se encontrar com problemas típicos da abordagem de certos naturalismos morais mais ortodoxos, como a falácia naturalista, em que se passa indevidamente de um "ser" para um "dever", ao situar o juízo avaliativo como oriundo de um juízo epistemológico que, em Nietzsche, consistiria no mundo como vontade de poder. É muito comum conferir um realismo não à situação em que nos encontramos no mundo, mas sim à vontade de poder, estabelecendo o raciocínio básico de se construir uma cognoscibilidade da vontade de poder, ou seja, a vontade de poder consiste genericamente em x, y e $z$, de modo que nossas ações devem refletir uma vontade forte correspondente $\mathrm{x}$, y e $z$, passando-se inadvertidamente de um 'ser' para um 'dever', inclusive estabelecendo uma concepção correspondencial de juízo de valor (cf. nossa nota acima sobre a advertência de Hume neste sentido). Não considero que Nietzsche tenha resolvido satisfatoriamente essa questão de falácia naturalista já formulada por um dos iniciadores do debate metaético (em 1903 com Moore e sua Principia Ethika). A vantagem do nosso argumento é justamente não assumir tal compromisso naturalista forte, dificilmente solucionáveis no interior da filosofia de Nietzsche; e 3) esboça-se a solução de um problema a partir do próprio problema que Nietzsche encontra em sua crítica, pois inclui o "ponto cego" como parte integrante para construção de objetividade. 
Em resumo, reivindicações de objetividade moral podem ser pensadas, portanto, por meio desse sistema autorreferencial, sem precisar apelar ao fundacionismo que remonta a um Eu, Sujeito ou Vontade Livre. Mesmo remontando a esses conceitos epistêmicos, e Nietzsche o faz com frequência, podemos sem dúvida compreendê-los naquele registro ficcionalista que escrevemos acima, ou seja, ficções sem valor cognitivo específica, mas que possuem usos práticos na organização do nosso mundo moral, portanto, ficções com funções regulativas, mas nunca constitutivas dos nossos juízos morais. Nesse sistema, além disso, não é preciso apelar também a um juízo de valor correspondencial ao mundo externo, a fim de justificar a veracidade ou falsidade dos seus juízos. Como vimos, Nietzsche é um autor que se desvincula nesse caso de uma concepção correspondencial dos juízos morais e, portanto, distante de um cognitivismo forte típico das pretensões naturalistas mais ortodoxas. Reivindica, porém, 'manter sob controle seus prós e contras' para poder dispor deles, por meio da categoria de autorreferencialidade. Em termos metaéticos, portanto, trata-se de assumir uma posição não-cognitivista com pretensões de objetividade moral. Essa posição é coerente com as pesquisas que venho fazendo em torno da noção de autogenealogia. Sem dúvida que valeria a pena detalhar o tema com base nas possibilidades de posições cognitivistas, principalmente as que exploram a 'teoria do erro' de Mackie. A estrutura autorreferencial, no entanto, parece plausível e contribui com algum sucesso no debate metaético contemporâneo.

Abstract: The objective of this article is to articulate the concepts of selfgenealogy and claim for moral objectivity, insofar I explore the fecundity of the 
notion of selfreferentiality from the selfgenealogical argument, as well as a deflationist conception of objectivity, according to which we must pay much more attention to the control over the content of moral judgments, and less to the correspondencial truth of such judgments. To do this, I take into account some categories from the contemporary debate in metaethics, and support the idea that Nietzsche engages himself in a non-cognitive position, while at the same time in a successful claim for moral objectivity.

Keywords: Self-genealogy; selfreferentiality; objectivity; metaethics.

\section{REFERÊNCIAS}

ARALDI, Clademir. Do niilismo ao naturalismo na moral. Pelotas: NEPFil, 2013.

BORN, M. Friedrich Nietzsche: Jenseits von Gut und Böse. Berlin: Walter de Gruyter, 2014.

BRITO, A. "Naturalismo moral”. In: Torres, João C. (org.) Manual de ética. Petrópolis: Vozes, pp. 342-364.

BROBJER, Thomas. Nietzsche's Ethics of Character: A Study of Nietzsche's Ethics and its Place in the History of Moral Thinking. Uppsala: Uppsala University, 1995.

. "Nietzsche's Affirmative Morality: an Ethics of Virtue". Journal of Nietzsche Studies, 26 (2003), pp. 64-78.

CONSTÂNCIO, João. "A Sort of Schema of Ourselves: on Nietzsche's 'Ideal' and 'Concept' of Freedom". In: Nietzsche-Studien 41 (2012), pp. 127-162.

CONWAY, D. "Genealogy and Critical Method". In: Schacht, R. Nietzsche, Genealogy, Morality. Berkeley/Los Angeles/London: University California Press, 1994.

COPP, D. "Varieties of moral naturalism". In: Filosofia 
Unisinos, 13 (suplem. 2), (out/2012), pp. 280-295.

DARWALL, S.; GIBBARD; A.; RAILTON, P. Metaética: algumas tendências. Trad. Janyne Sattler. Florianópolis: Editora UFSC, 2013.

FINKEN, B. "Nietzsche versus the Genetic Fallacy". In: Journal of Nietzsche Studies, v. 43, n. 2 (Autumn 2012), pp. 305-315.

HATAB, Lawrence. On the Genealogy of Morality. Cambridge: Cambridge University Press, 2008.

HEINRICHS, Bert; HEINRICHS, Jan-Hendrik. Metaethik. Klassische Texte. Berlin: Suhrkamp, 2016.

HUME, D. Tratado da Natureza Humana. (TNH). São Paulo: Unesp, 2000.

JANAWAY, Christopher. Beyond Selflessness. Oxford: Oxford: University Press, 2007.

JANAWAY, C.; ROBERTSON, S. (orgs.) Nietzsche, Naturalism and Normativity. Oxford: Oxford University Press, 2012.

LEITER, Brian. "Nietzsche's Metaethics: Against the Privilege Reading's. In: European Journal of Philosophy 8 (2000), pp. 277-297.

Nietzsche on Morality. London/New York: Routledge, 2002.

"Nietzsche's naturalism reconsidered". In: JAMES, K.; RICHARDSON, J. (orgs.). Oxford Handbook of Nietzsche. Oxford: Oxford University Press, 2009. 
LEITER, Brian; SINHABABU, Neil. (orgs.) Nietzsche and Morality. Oxford: Oxford University Press, 2012.

LOPES, Rogério. "Há espaço para uma concepção não moral da normatividade prática em Nietzsche? Notas sobre um debate em andamento". In: Cadernos Nietzsche 33 (2013) pp. 89-134.

. "Ceticismo e vida contemplativa". UFMG, 2008 (Tese de doutorado).

LOSSI, A. „Philosophie als Selbstgestaltung? Umwertung und Selbstverständnis im Ausgang von Nietzsches von den ,Vorurtheilen der Philosophen' in Jenseits von Gut und Böse". In: BORN, M. (Hrsg.). Texturen des Denkens. Nietzsches Inszenierung der Philosophie in Jenseits von Gut und Böse. Berlin/Boston: Walter de Gruyter, 2013. pp. 107-122.

MACKIE, John. Ethics: Inventing Right and Wrong. London: Penguin Books, 1990.

MATTOS, Fernando C. Nietzsche: perspectivismo e democracia. São Paulo: Saraiva, 2013.

MENDONÇA, Wilson. "Questões metaéticas". In: Torres, João C. (org.) Manual de ética. Petrópolis: Vozes, pp. 153-173.

MOORE, G.E. Principia Ethica. NY: Cambridge University Press, 1903.

MILLER, A. An Introduction to Contemporary Metaethics. Cambridge: Polity, 2013.

Müller, E. „Von der Umwerthung zur Autogenealogie. Die 
Götzen-Dämmerung im Kontext des Spätwerks“. In: GERHARDT, V.; RESCHKE, R. (Hg.): Nietzsche im Film- Projektionen und Götzen-Dämmerung, Nietzscheforschung, 16 (2008), pp. 141-149.

MÜLLER, E.; BENNE, Cf. Ohnmacht des Subjekts Marcht der Persönlichkeit. Basel: Schwabe Verlag, 2014.

NIETZSCHE, F. Sämtliche Werke. Kritische Studienausgabe in 15 Bänden. (KSA) Hrsg. Giorgio Colli und Mazzino Montinari. Berlin/New York: DTV \& Walter de Gruyter, 1999.

PIAZZESI, Chiara. "Was Alles Liebe genannt wird' ('Tudo o que é chamado de amor'): FW/GC 14 como exemplo de exercício pré-genealógico". In: Cadernos Nietzsche 27 (2010), pp. 73-115.

RICHARDSON, John. "Nietzsche and Transcendental Argument". In: Kriterion 128, v.1 (2013), pp. 287-305.

Rupschus, A. Nietzsches Problem mit den Deutschen. Wagners Deutschtum und Nietzsches Philosophie. Berlin/Boston: Walter de Gruyter, 2013.

Saar, M. Genealogie als Kritik. Geschichte und Theorie des Subjekts nach Nietzsche und Foucault. Frankfurt/New York: Campus Verlag, 2007.

SCHACHT, Richard (Org.) Nietzsche, Genealogy, Morality: essays on Nietzsche's Genealogy of morals. Berkeley/Los Angeles/London: University California Press, 1994.

"O naturalismo de Nietzsche." In: Cadernos Nie- 
tzsche 29 (2011), pp. 35-76.

SCHROEDER, M. Noncognitivism in Ethics. London/New York: Routledge, 2010.

SERRES, Michel. Der Parasit. Frankfurt am Main: Suhrkamp, 1987

SHAFER-LANDAU, R. Moral realism: a defense. Oxford: Oxford University Press, 2005.

Sommer, Andreas. Nietzsche-Kommentar. Der Fall Wagner, Götzen-Dämmerung. Berlin/Boston: Walter de Gruyter, 2012.

STAHL, Titus. Einführung in die Metaethik. Stuttgart: Reclam, 2013.

Stegmaier, Werner. Nietzsches „,Genealogie der Moral“, Darmstadt: WBG, 2010.

- Nietzsches Befreiung der Philosophie. Berlin/Boston: Walter de Gruyter, 2012.

. Orientierung im Nihilismus - Luhmann meets Nietzsche. Berlin/Boston: de Gruyter, 2016.

TONGEREN, Paul v. A moral da crítica de Nietzsche à moral. Estudo sobre "Para além de bem e mal". Trad. Jorge L. Viesenteiner. Curitiba: Champagnat, 2012.

VECCHIA, Ricardo B. "O(s) perspectivismo(s) de Nietzsche". Unicamp, 2014 (Tese de doutorado).

VIESENTEINER, Jorge L. "Estrutura formal e semântica do argumento autogenealógico". In: Cadernos de Filosofia Alemã, v. 20, n. 2, (2015), pp. 105-119. 
. "Sobre autoencenação e autogenealogia no Crepúsculo dos ídolos de Nietzsche". In: Estudos Nietzsche, v. 5, n. 2 (2014), pp. 189-214. 